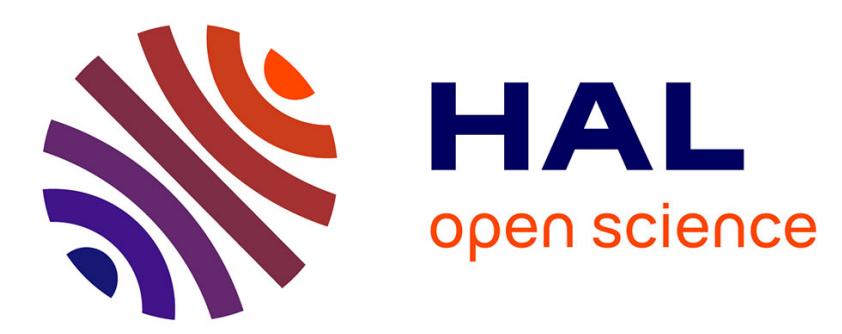

\title{
A differential model of controlled cardiac pacemaker cell
} Karima Djabella, Michel Sorine

\section{To cite this version:}

Karima Djabella, Michel Sorine. A differential model of controlled cardiac pacemaker cell. 6th IFAC Symposium on Modelling and Control in Biomedical Systems, Sep 2006, Reims, France. inria00001196v2

\section{HAL Id: inria-00001196 https://hal.inria.fr/inria-00001196v2}

Submitted on 4 Apr 2006

HAL is a multi-disciplinary open access archive for the deposit and dissemination of scientific research documents, whether they are published or not. The documents may come from teaching and research institutions in France or abroad, or from public or private research centers.
L'archive ouverte pluridisciplinaire HAL, est destinée au dépôt et à la diffusion de documents scientifiques de niveau recherche, publiés ou non, émanant des établissements d'enseignement et de recherche français ou étrangers, des laboratoires publics ou privés. 


\title{
A DIFFERENTIAL MODEL OF CONTROLLED CARDIAC PACEMAKER CELL
}

\author{
Karima Djabella* Michel Sorine* \\ * INRIA Rocquencourt / B.P.105.78153 Le Chesnay Cedex, \\ France
}

\begin{abstract}
A differential model of a cardiac pacemaker cell with only ten state variables is proposed. It is intended for $0 \mathrm{D}$ or $3 \mathrm{D}$ simulation of the heart under the vagal control of the autonomous nervous system. Three variables are used to describe the membrane (membrane potential and two gate variables of ionic channels), taking into account the dynamics of the main ionic currents (inward sodium, L-type calcium and outward potassium), $\mathrm{Na}^{+} / \mathrm{Ca}^{2+}$ exchangers and $\mathrm{Na}^{+} / \mathrm{K}^{+}$pumps. The remaining seven variables are associated with the fluid compartment model that includes $\mathrm{Ca}^{2+}$ binding by myoplasmic proteins, and the intracellular concentrations of free Calcium, Sodium and Potassium. Despite its moderate number of state variables, this model includes the main processes thought to be important in pacemaking on the cell scale and predicts the experimentally observed ionic concentration of calcium, sodium and potassium, action potential and membrane currents. The control by the calcium of the pacemaking activity is also considered. Copyright (C)2006 IFAC
\end{abstract}

Keywords: Electrical activity, Nonlinear systems, Dynamic modelling, Frequency control.

\section{INTRODUCTION}

There are many mathematical models of the electrophysiology of the different types of cardiac cells. For models of human ventricular or atrial cells, see e.g. (Tusscher et al., 2004; Nygren et $a l ., 1998)$ and the references herein. The sinoatrial node cells and their pacemaker activity, considered here, have been studied in (Demir et al., 1994; Dokos et al., 1996; Dokos et al., 1998; Zhang et al., 2000; Kurata et al., 2002). These models result from iterations between mathematics and experimentation on the cell scale where detailed characteristics of isolated ion channels can now be measured. They are based on the ionic current model of (Hodgkin and Huxley, 1952), but the cardiac myocytes being far more complex than the squid giant axon considered by this first model, their complexity is high with e.g. 28 state variables for the model in (Kurata et al., 2002).

Recently, model-based image and signal processing on the heart scale has become an important goal as in (CardioSense3D, 2006). In such project, models are not only needed in direct computations to gain insights and for their predictive capabilities, but also in inverse problems to estimate state and parameters from measurements. In that case it is necessary to predict the shape of action potential (AP) for electrocardiogram interpretation, as well as the concentration of calcium bound on Troponin C, responsible for electromechanical coupling at the origin of heart deformations seen in the images. It is then necessary to represent also some intracellular calcium buffering, as will be done here, a special attention being paid to model complexity in order to have a good tradeoff 
between the descriptive power of the model and the well-posedness of associated inverse problems.

In this paper, a model for a cardiac pacemaker cell is proposed. It is realistic enough to exhibit many of the characteristics of larger pacemaker cell models, and yet, is simple enough with only ten state variables. It has furthermore a sound asymptotic behaviour without drifts of the state, a useful property for multi-beat simulations. The same model structure has been used in (Djabella and Sorine, 2005) to represent excitation-contraction coupling in a ventricular cell. It consists of two parts: 1) a cell membrane with capacitance, voltage-dependent ion channels, electrogenic pump and exchanger, the ionic currents model being derived using conservation laws as in (Endresen et al., 2000), and 2) a lumped compartmental model that accounts for intracellular changes in concentrations of $\mathrm{Na}^{+}, \mathrm{K}^{+}$ (Hund et al., 2001) and the main processes that regulate intracellular calcium concentration: release and uptake by the sarcoplasmic reticulum (SR), buffering in the SR (Tusscher et al., 2004) and in the bulk cytosol (Shannon et al., 2004).

The ionic currents that control membrane depolarization during diastole and then the heart rate, are still a matter of debate. (DiFrancesco, 1993) argues that the hyperpolarization activated current $\left(i_{f}\right)$ is the only current that can generate and control the slow depolarization of pacemaker cells. This current is normally carried by $\mathrm{Na}^{+}$and $\mathrm{K}^{+}$. (Guo et al., 1995) reported another current, called the sustained inward current $i_{s t}$, where the major charge carrier is believed to be $\mathrm{Na}^{+}$. Also a $\mathrm{Ca}^{2+}$ "window" current has been observed in rabbit sinoatrial node cells (Denyer and Brown, 1995). It is possible that any of these currents, or a combination of them, is responsible for membrane depolarization during diastole.

During diastole the electrochemical driving forces produce outward $\mathrm{K}^{+}$currents and inward $\mathrm{Na}^{+}$ and $\mathrm{Ca}^{2+}$ currents, and the driving force for $\mathrm{Ca}^{2+}$ is much larger than that for $\mathrm{Na}^{+}$(Endresen et al., 2000). This implies that a significant background influx of $\mathrm{Ca}^{2+}$ is possible during diastole, and that this current might be responsible for pacemaking activity in sinoatrial node cells (Boyett et al., 2001). The conductance for this current is denoted $\bar{I}_{b, C a}$ and used in the proposed model to control the voltage-dependent calcium current $I_{C a, t} . \bar{I}_{b, C a}$ is responsible for the slow diastolic depolarization, and appears to have control capability of the pacemaker activity. In fact, changes in the cycle length of the pacemaker AP will be observed in an almost linear relationship with $\bar{I}_{b, C a}$. Then, we conclude that the autonomous nervous system interacts almost linearly in the regulation of heart rate as assumed in (Warner and Russell, 1969).

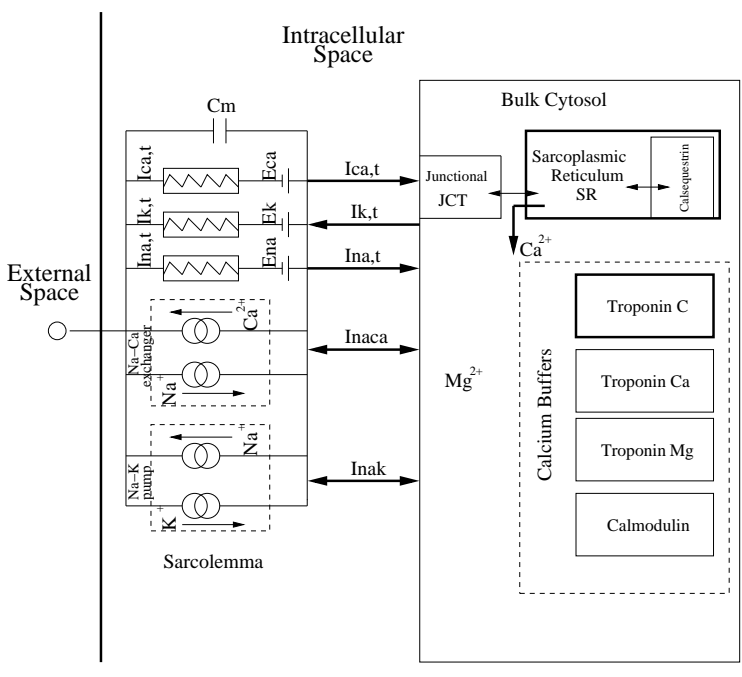

Fig. 1. A representation of the model of a cardiac pacemaker cell: electrical equivalent circuit for the sarcolemma and fluid compartment

The paper is organized as follows: the model is described in Section 2. Section 3 shows some simulation results. A discussion and conclusions are presented in Sections 4 and 5 respectively.

\section{MODEL DESCRIPTION}

The mathematical model is a nonlinear system of ten first order ordinary differential equations. The detailed equations, parameters values and abbreviations used are presented in the APPENDIX.

Figure 1 shows the lumped electrical equivalent circuit for the sarcolemma and the fluid compartment system of a single pacemaker cardiac cell. The membrane model includes both the potential-mediated ion channels responsible for the dynamic aspects of the membrane AP (inward sodium, L-type calcium and outward potassium) and $\mathrm{Na}^{+} / \mathrm{Ca}^{2+}$ exchangers, $\mathrm{Na}^{+} / \mathrm{K}^{+}$pumps. The fluid compartment is modelled by seven differential equations, three of them describing the intracellular concentrations of free Calcium, Sodium and Potassium. The remaining four equations describe the binding of $\mathrm{Ca}^{2+}$ to specific sites on the myoplasmic troponin and calmodulin proteins, taking into account the competition between $\mathrm{Ca}^{2+}$ and $\mathrm{Mg}^{2+}$. The $\mathrm{Ca}^{2+}$ buffering system is very important for the regulation and limitation of free intracellular $\mathrm{Ca}^{2+}$ concentration transients.

\section{RESULTS}

The dynamic behavior of the cell model was computed by solving the system of nonlinear ordinary differential equations with a second order modified Rosenbrock method with variable steplength. The initial conditions are listed in the table 1. 

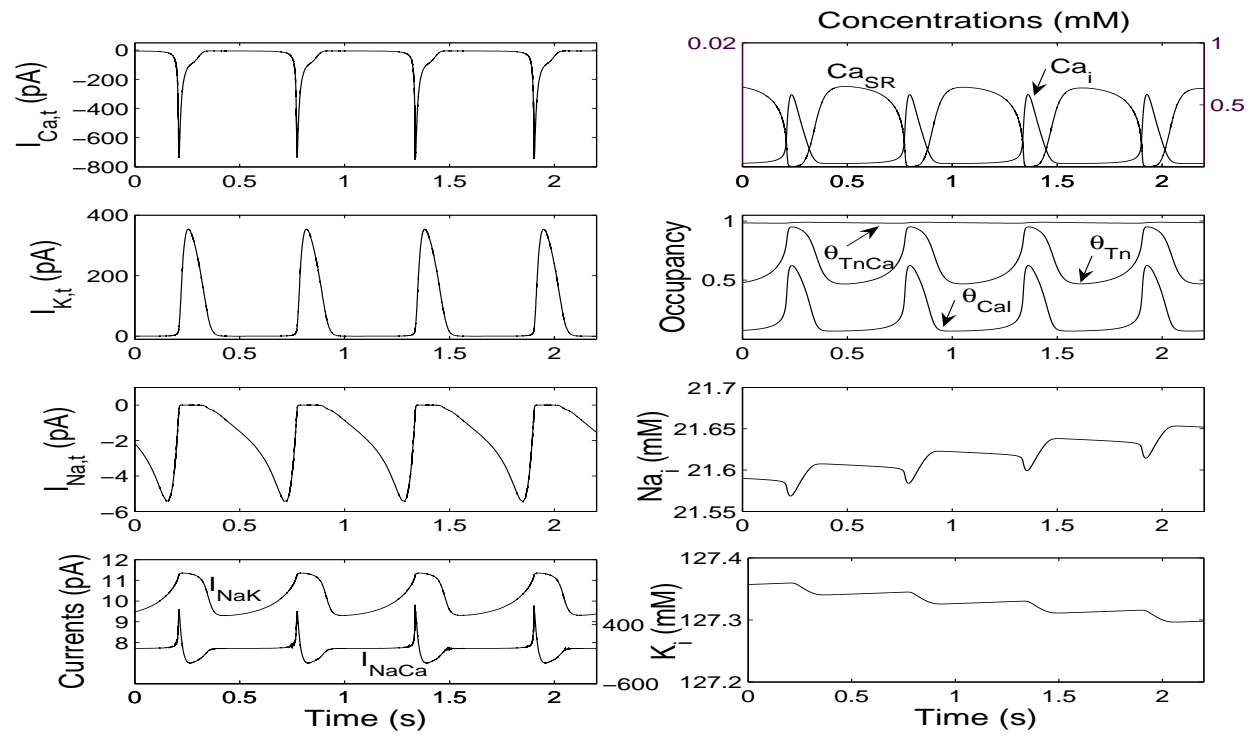

Fig. 3. Computed spontaneous AP and ionic currents (left) and intracellular $\mathrm{Ca}^{2+}$ dynamics (right)

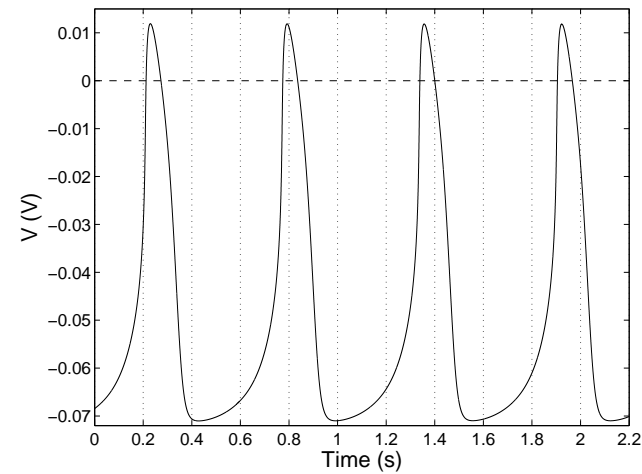

Fig. 2. Spontaneous action potential

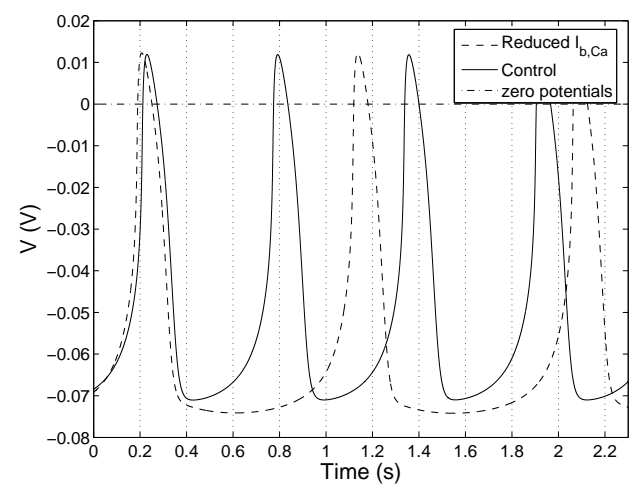

Fig. 4. Effect of a reduced $\bar{I}_{b, C a}$ on action potential

Figure 2 shows the computed AP that had a cycle length, amplitude, duration (measured at $-30 \mathrm{mV}$ ) and maximal diastolic potential of $550 \mathrm{~ms}, 85 \mathrm{mV}$, $120 \mathrm{~ms}$ and $-71 \mathrm{mV}$, respectively. This simulated pacemaker AP has a reasonable shape compared with those recorded experimentally.

Figure 3 shows, on the left, the computed temporal behaviour of sarcolemmal ionic currents. On

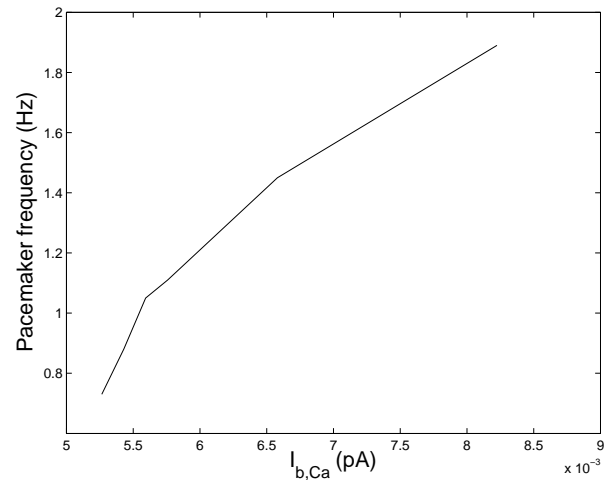

Fig. 5. The relationship between the pacemaker frequency and the amplitude of the pacemaker current: the control effect

the right, it shows the intracellular $\mathrm{Ca}^{2+}$ dynamics including the changes in $\mathrm{Ca}^{2+}$ concentration in the $\mathrm{SR}$, the associated changes in the occupancy ratio of $\mathrm{Ca}^{2+}$ buffers and the changes in $\mathrm{Na}_{i}$ and $K_{i}$ during pacemaker activity. These computed waveform changes during spontaneous AP are very similar to those recorded experimentally (Demir et al., 1994).

In Fig. 4, the AP computed under control conditions is compared with that computed when the pacemaker current $\bar{I}_{b, C a}$ was affected. It shows:

- a cycle length increase from 550 to $900 \mathrm{~ms}$,

- an AP amplitude slight change from 85 to $88 \mathrm{mV}$, - an AP duration increase, at $-30 m V$, from 120 to $130 \mathrm{~ms}$, and

- a maximal diastolic potential decrease of $5 \mathrm{mV}$. These changes are qualitatively similar to those observed experimentally in rabbit sinoatrial node cells (Boyett et al., 2001). 

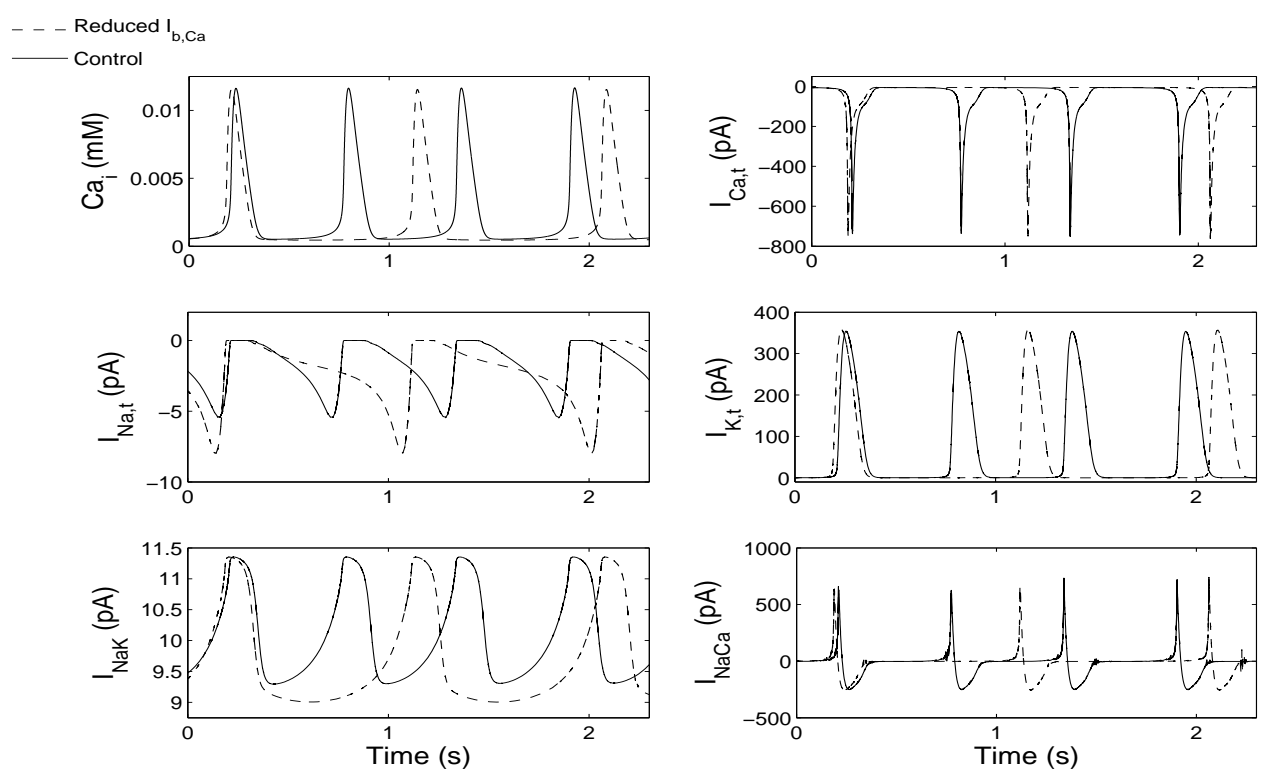

Fig. 6. $C a^{2+}$ transients and ionic currents computed under control conditions and for a reduced $\bar{I}_{b, C a}$

Figure 5 shows the relationship between the pacemaker frequency and the amplitude of the pacemaker current $\bar{I}_{b, C a}$ : it appears to be approximately linear. This has an important consequence: there is no need for a more complex model for quantitative simulations of pacemaker under the control of the autonomic nervous system. This frequency control can be described fairly well by assuming that the sympathetic-parasympathetic balance interacts almost linearly on the heart rate as assumed in (Warner and Russell, 1969).

Figure 6 shows the effect of a reduced pacemaker current $\bar{I}_{b, C a}$ on the simulated intracellular calcium concentration and ionic currents. In this case, there is no slight change in the $\mathrm{Ca}^{2+}$ transients shapes or in transmembrane ionic currents waveforms (there is a small decrease in the $I_{N a, t}$ current amplitude): they were only shifted. In conclusion, only pacemaking rate was affected. In the present paper $I_{C a, t}$ means $I_{C a, L}$ (Djabella and Sorine, 2005) and the $\bar{I}_{b, C a}$ affects this current (eq. 6 ), therefore, the simulations are consistent with the experimental data (Boyett et al., 2001).

\section{DISCUSSION}

A simple model for a cardiac pacemaker cell has been presented. It involves only $\mathrm{Na}^{+}, \mathrm{K}^{+}$ and $\mathrm{Ca}^{2+}$ ions, their respective channels, the $\mathrm{Na}^{+} / \mathrm{Ca}^{2+}$ exchanger, and the $\mathrm{Na}^{+} / \mathrm{K}^{+}$pump. It also includes a description of the dynamics of the main calcium buffers in the bulk cytosol and in the SR, and it takes into account the calcium uptake and release from SR.

The model is able to produce sinoatrial node AP, the behavior of the most important currents and the intracellular $\mathrm{Ca}^{2+}$ dynamics (concentration changes, SR $\mathrm{Ca}^{2+}$ uptake and release, and $\mathrm{Ca}^{2+}$ buffering) involved during normal pacemaking.

The contribution of the currents to the pacemaker activity is still ill known despite many studies (Rasmusson et al., 1990; Demir et al., 1994; Kurata et al., 2002). All of them agree that the calcium plays an important role in the slow depolarization of the cardiac pacemaker potential. In recent years much attention has been focused on the possibility that $\mathrm{Ca}^{2+}$ can control the pacemaker activity of the sinoatrial node. In this article, using computer simulations, it has been shown that a significant background influx of $\mathrm{Ca}^{2+}$ may be important in the changes in the AP and pacemaker activity (Boyett et al., 2001).

The proposed model and simulations can provide guidance for future developments of more realistic controlled cardiac pacemaker cell for use in models of the intact sinoatrial node or in whole heart models in three dimensions.

\section{CONCLUSION}

A differential model of cardiac pacemaker cell has been presented. Simulations of the electrical pacemaker activity and associated cytosolic ion concentration changes appear realistic. They demonstrate the control of the pacemaker activity by the calcium, so that the modulation of this activity by the autonomous nervous system can be explained fairly well by assuming that the sympatheticparasympathetic system interacts linearly on the heart rate via a calcium input. 
Due to its sound asymptotic behavior without drifts of the state and to its medium complexity, this model can provide guidance for future modelling work on the controlled cardiac pacemaker cells in multi-beat simulations from the cell to the heart scales.

\section{APPENDIX}

The proposed model of cardiac pacemaker cell is the following system of differential equations:

$$
\begin{aligned}
\frac{d V}{d t} & =-\frac{I_{K, t}+I_{N a, t}+I_{C a, t}+I_{N a K}+I_{N a C a}}{C_{m}} \\
\frac{d K_{i}}{d t} & =\frac{2 I_{N a K}-I_{K, t}}{F V_{C}} \\
\frac{d N a_{i}}{d t} & =-\frac{I_{N a, t}+3 I_{N a K}+3 I_{N a C a}}{F V_{C}} \\
\frac{d C a_{i}}{d t} & =\frac{2 I_{N a C a}-I_{C a, t}}{2 F V_{C}}+J_{l e a k}+J_{r e l}-J_{u p} \\
-\sum & B_{b} \frac{d \theta_{b}}{d t}, I_{B}=\{T n, C a l, T n C a\} \\
\frac{d g_{X}}{d t}= & \frac{g_{X \infty}-g_{X}}{\tau_{g_{X}}}, \quad X \in\{N a, K\} \\
\frac{d \theta_{T n}}{d t}= & k_{T n}^{o n}\left|C a_{i}\right|_{+}\left(1-\theta_{T n}\right)-k_{T n}^{o f f} \theta_{T n} \\
\frac{d \theta_{C a l}}{d t}= & k_{C a l}^{o n}\left|C a_{i}\right|_{+}\left(1-\theta_{C a l}\right)-k_{C a l}^{o f f} \theta_{C a l} \\
\frac{d \theta_{T n C a}}{d t} & =k_{T n C a}^{o n}\left|C a_{i}\right|_{+}\left(1-\theta_{T n C a}-\theta_{T n M g}\right) \\
& -k_{T n C a}^{o f f} \theta_{T n C a} \\
\frac{d \theta_{T n M g}}{d t} & =k_{T n M g}^{o n}\left|M g_{i}\right|_{+}\left(1-\theta_{T n C a}-\theta_{T n M g}\right) \\
& -k_{T n M g}^{o f f} \theta_{T n M g}
\end{aligned}
$$

The gate dynamics are defined by

$$
\begin{aligned}
g_{X \infty} & =\frac{1}{2}\left[1+\tanh \left(\frac{V-V_{g_{X}}}{R T / 2 F}\right)\right], \\
\tau_{g_{X}} & =\frac{\tau_{X}}{\cosh \left(\frac{V-V_{g_{X}}}{R T / 2 F}\right)}, \quad X \in\{N a, K, d, m\}
\end{aligned}
$$

where $X=d, m$ represent fast $C a, N a$ activation gating, denoted as usual $d_{\infty}=g_{d \infty}, m_{\infty}=g_{m \infty}$. Setting

$$
V_{X}=\frac{R T}{z_{X} F} \log \left|\frac{X_{e}}{X_{i}}\right|, X \in\{C a, N a, K\},
$$

the currents through the membrane are then:

$$
\begin{aligned}
I_{K, t} & =\bar{I}_{K} g_{K} \sinh \left(\frac{V-V_{K}}{2 R T / F}\right) \\
I_{N a, t} & =\bar{I}_{N a} g_{N a} m_{\infty} \sinh \left(\frac{V-V_{N a}}{2 R T / F}\right) \\
I_{C a, t} & =\left[\bar{I}_{C a}\left(1-g_{K}\right) d_{\infty}+\bar{I}_{b, C a}\right] \sinh \left(\frac{V-V_{C a}}{R T / F}\right) \\
I_{N a K} & =\bar{I}_{N a K} \tanh \left(\frac{V+2 V_{K}-3 V_{N a}-V_{A T P}}{2 R T / F}\right) \\
I_{N a C a} & =\bar{I}_{N a C a} \sinh \left(\frac{V+2 V_{C a}-3 V_{N a}}{2 R T / F}\right)
\end{aligned}
$$

Finally, the CICR mechanism is described using

$$
J_{u p}=Q_{u p} J_{\max } \frac{\left|\frac{C a_{i}}{K_{m f}}\right|^{H}-\left|\frac{C a_{S R}}{K_{m r}}\right|^{H}}{1+\left|\frac{C a_{i}}{K_{m f}}\right|^{H}+\left|\frac{C a_{S R}}{K_{m r}}\right|^{H}}
$$

$$
\begin{aligned}
& J_{\text {rel }}=K_{\text {rel }} d_{\infty}\left(C a_{S R}-C a_{i J C T}\right) \\
& J_{\text {leak }}=K_{\text {leak }}\left(C a_{S R}-C a_{i J C T}\right) \\
& C a_{i J C T}=\frac{B B_{J C T}\left|C a_{i}\right|_{+}}{\left|C a_{i}\right|_{+}+K_{J C T}} \\
& C a_{S R}+\frac{B B_{S R}\left|C a_{S R}\right|_{+}}{\left|C a_{S R}\right|_{+}+K_{S R}}= \\
& \frac{V_{C}}{V_{S R}}\left(C a_{T}-C a_{i}-\sum_{b \in I_{B}} B_{b} \theta_{b}-C a_{i J C T}\right) \\
& C a_{T}=\frac{1}{2}\left(\frac{C_{m}}{F V_{C}}\left(V-V_{e x t}\right)-N a_{i}-K_{i}\right) \\
& V_{e x t}=-\frac{F V_{C}}{C_{m}}\left(N a_{e}+K_{e}+2 C a_{e}\right)
\end{aligned}
$$

\section{REFERENCES}

Boyett, M. R., H. Zhang, A. Garny and A. V. Holden (2001). Control of the pacemaker activity of the sinoatrial node by intracellular $\mathrm{ca}^{2+}$. experiments and modelling. Phil. Trans. The Royal Society 359, 1091-1110.

CardioSense3D (2006). An INRIA Large Initiative Action. //www-sop.inria.fr/CardioSense3D.

Demir, S. S., J. W. Clark, C. R. Murphey and W. R. Gilles (1994). A mathematical model Table 1 Initial conditions

\begin{tabular}{lll} 
Variables & Initial values & Units \\
\hline$V_{0}$ & $-51.410^{-3}$ & $V$ \\
$K_{i 0}$ & 127.8 & $m M$ \\
$N a_{i 0}$ & 20.7 & $m M$ \\
$C a_{i 0}$ & 0.001 & $m M$ \\
$\theta_{T n 0}$ & 0.0451 & \\
$\theta_{T n C a 0}$ & 0.139 & \\
$\theta_{T n M g 0}$ & 0.0003 & \\
$\theta_{C a l 0}$ & 0.0031 & \\
$g_{K 0}$ & 0.074 & \\
$g_{N a 0}$ & 0.029 & \\
\hline
\end{tabular}

Table 2 Abbreviations used in the text

\begin{tabular}{ll} 
Abbrev. & Definitions \\
\hline$V$ & Action potential \\
$V_{e x t}$ & External stimulus voltage \\
$I_{X, t}$ & Total X current through all channels \\
$I_{N a C a}$ & $N a^{+}-\mathrm{Ca}^{2+}$ exchanger current \\
$I_{N a K}$ & $N a^{+}-K^{+}$pump current \\
$g_{K}$ & Potassium activation gating \\
$g_{N a}$ & Sodium activation gating \\
$d_{\infty}$ & Fast Calcium activation gating \\
$m_{\infty}$ & Fast Sodium activation gating \\
$J_{r e l}$ & Calcium-Induced Calcium Release current \\
$J_{u p}$ & Pump current taking up calcium in the $\mathrm{SR}$ \\
$J_{l e a k}$ & Leakage current from SR to the cytoplasm \\
$X_{i}$ & Intracellular concentration of the free ion $X$ \\
$X_{e}$ & External concentration of the ion free $X$ \\
$C a_{T}$ & Total calcium concentration in the cell \\
$C a_{S R}$ & Free calcium concentration in the SR \\
$\theta_{T n}$ & Fraction of Troponin-C sites bound with Ca \\
$\theta_{T n C a}$ & Fraction of Troponin-Ca sites bound with Ca \\
$\theta_{T n M g}$ & Fraction of Troponin-Mg sites bound with $\mathrm{Mg}$ \\
$\theta_{C a l}$ & Fraction of Calmodulin sites bound with Ca \\
$C a_{i J C T}$ & SR Calcium buffered in the junction \\
\hline &
\end{tabular}


Table 3 Model parameters

\begin{tabular}{|c|c|c|}
\hline Parameter & Value & Unit \\
\hline$V_{C}$ & 16.404 & $p L$ \\
\hline$V_{S R}$ & 1.094 & $p L$ \\
\hline$F$ & 96.486 & $\mathrm{Cmmol}^{-1}$ \\
\hline$V_{m}$ & $-56.8610^{-3}$ & $V$ \\
\hline$V_{d}$ & $-510^{-3}$ & $V$ \\
\hline$V_{g_{K}}$ & $-2610^{-3}$ & $V$ \\
\hline$V_{g_{N a}}$ & $-71.5510^{-3}$ & $V$ \\
\hline$\tau_{N a}=\tau_{K}$ & 0.2 & $s$ \\
\hline$V_{A T P}$ & $-45010^{-3}$ & $V$ \\
\hline$C_{m}$ & 22 & $p F$ \\
\hline$R$ & $8.31410^{-3}$ & $\mathrm{Jmmol}^{-1} K^{-1}$ \\
\hline$T$ & 310 & $K$ \\
\hline$z_{N a}=z_{K}$ & 1 & \\
\hline$z_{C a}$ & 2 & \\
\hline $\bar{I}_{N a}$ & 11.27 & $p A$ \\
\hline $\bar{I}_{K}$ & 164.5 & $p A$ \\
\hline $\bar{I}_{C a}$ & 131 & $p A$ \\
\hline $\bar{I}_{b, C a}$ & 0.0074 & $p A$ \\
\hline $\bar{I}_{N a K}$ & 11.46 & $p A$ \\
\hline $\bar{I}_{N a C a}$ & 7000 & $p A$ \\
\hline$K_{e}$ & 5.4 & $m M$ \\
\hline$N a_{e}$ & 140 & $m M$ \\
\hline$C a_{e}$ & 2 & $m M$ \\
\hline$M g_{i}$ & 1 & $m M$ \\
\hline$K_{\text {leak }}$ & $510^{-8}$ & $s^{-1}$ \\
\hline$H$ & 1.787 & \\
\hline$K_{m f}$ & $0.24610^{-3}$ & $m M$ \\
\hline$K_{m r}$ & 1.7 & $m M$ \\
\hline$J_{\max }$ & $28610^{-3}$ & $m M s^{-1}$ \\
\hline$Q_{u p}$ & $2.610^{-5}$ & \\
\hline$K_{\text {rel }}$ & $2510^{-2}$ & $s^{-1}$ \\
\hline$k_{T n}^{o n}$ & $32.710^{3}$ & $m M^{-1} s^{-1}$ \\
\hline$k_{T n}^{\stackrel{I}{o f f} f}$ & 19.6 & $s^{-1}$ \\
\hline$B_{T n}$ & $7010^{-8}$ & $m M$ \\
\hline$k_{T n C a}^{o n}$ & $2.3710^{3}$ & $m M^{-1} s^{-1}$ \\
\hline$k_{T n C a}^{o f f}$ & 0.032 & $s^{-1}$ \\
\hline$B_{T n C a}$ & $14010^{-8}$ & $m M$ \\
\hline$k_{T n M g}^{o n}$ & $0.00310^{3}$ & $m M^{-1} s^{-1}$ \\
\hline$k_{T n M g}^{o f f}$ & 3.33 & $s^{-1}$ \\
\hline$B_{T n M g}$ & $14010^{-3}$ & $m M$ \\
\hline$k_{C a l}^{o n}$ & $3410^{3}$ & $m M^{-1} s^{-1}$ \\
\hline$k_{\mathrm{Cal}}^{o f f}$ & 238 & $s^{-1}$ \\
\hline$B_{C a l}$ & $2410^{-8}$ & $m M$ \\
\hline$K_{J C T}$ & $1310^{-3}$ & $m M$ \\
\hline$B_{J C T}$ & $4.610^{-3}$ & $m M$ \\
\hline$K_{S R}$ & 0.0065 & $m M$ \\
\hline$B_{S R}$ & 0.14 & $m M$ \\
\hline
\end{tabular}

of a rabbit sinoatrial node cell. Am J Physiol Heart Cell Physiol 266(35), C832-C852.

Denyer, J. C. and H. F. Brown (1995). Calcium 'window' current in rabbit sino-atrial node cells. Journal of Physiol. 429, 405-424.

DiFrancesco, D. (1993). Pacemaker mechanisms in cardiac tissue. Annual Review of Physiol. $\mathbf{5 5}, 455-472$

Djabella, K. and M. Sorine (2005). Differential model of the excitation-contraction coupling in a cardiac cell for multicycle simulations. In: EMBEC'05. Prague.

Dokos, S., B. G. Celler and N. H. Lovell (1996). Ion currents underlying sinoatrial node pacemaker activity: a new single cell mathematical model. Journal of Theoretical Biology 181, 245-272.
Dokos, S., N. H. Lovell and B. G. Celler (1998). Review of ionic models of vagal-cardiac pacemaker control. Journal of Theoretical Biology 192(3-7), 265-274.

Endresen, L. P., K. Hall, J. S. Hoye and J. Myrheim (2000). A theory for the membrane potential of living cells. Eur Biophys $J$ 29, 90-103.

Guo, J., K. Ono and A. Noma (1995). A sustained inward current activated at the diastolic potential range in rabbit sinoatrial node cells. Journal of Physiol. 483, 1-13.

Hodgkin, A. L. and A. F. Huxley (1952). A quantitative description of membrane current and its application to conduction and excitation in nerve. Journal of physiology 117, 500-544.

Hund, T. J., J. P. Kucera, N. F. Otani and Y. Rudy (2001). Ionic charge conservation and long-term steady state in the LuoRudy dynamic cell model. Biophys. Journal 81, 3324-3331.

Kurata, Y., I. Hisatome, S. Imanishi and T. Shibamoto (2002). Dynamical description of sinoatrial node pacemaking: improved mathematical model for primacy pacemaker cell. Am J Physiol Heart Circ Physiol 283, H2074-H2101.

Nygren, A., C. Fiset, L. Firek, J. W. Clark, D. S. Lindblad, R. B. Clark and W. R. Giles (1998). Mathematical Model of an Adult Human Atrial Cell : The Role of K+ Currents in Repolarization. Circ Res 82(1), 63-81.

Rasmusson, R. L., J. W. Clark, W. R. Giles, E. F. Shibata and D. L. Campbell (1990). A mathematical model of a bullfrog cardiac pacemaker cell. Am J Physiol Heart Circ Physiol 259(28), H352-H369.

Shannon, T. R., F. Wang, J. Puglisi, C. Weber and D. M. Bers (2004). A mathematical treatment of integrated ca dynamics within the ventricular myocyte. Biophys J 87, 3351-3371.

Tusscher, K. H. W. J. Ten, D. Noble, P. J. Noble and A. V. Panfilov (2004). A model for human ventricular tissue. Am J Physiol Heart Circ Physiol 286, 1573-1589.

Warner, H. R. and R. O. Russell (1969). Effect of combined sympathetic and vagal stimulation on heart rate in the dog. Circ. Res. 24(4), 567-573.

Zhang, H., A. V. Holden, I. Kodama, H. Honjo, M. Lei, T. Varghese and M. R. Boyett (2000). Mathematical models of action potentials in the periphery and center of the rabbit sinoatrial node. Am J Physiol Heart Circ Physiol 279. H397-H421. 